natural sciences in the German-language region, including Austria and Switzerland. The East German Academy of Sciences, which until 1990 was the main scientific institution in the communist German Democratic Republic, has been closed down.

None of these organizations can claim to speak for German science as a whole, either at home or abroad. Nor can they fulfil the advisory role undertaken by national academies elsewhere. The Deutsche Forschungsgemeinschaft (DFG), Germany's main research agency, has done some of this in the past. But as a funding agency affiliated to the government, it cannot act as the independent voice of the scientific community in Germany.

A national academy has been on the radar of Germany's scientific leaders ever since reunification. In 2004 the Wissenschaftsrat - a council of the great and the good that currently advises the government on science policy - asked the regional academies to come up with their ideas for one. Under the academies' as-yet-unpublished proposal, the national academy would comprise a 200-strong council, appointed by the regional academies. It would generate advice for the government through ad-hoc working groups with appropriate external expertise. The details of how this will be done are still being debated within the scientific community, but the outline proposal will be considered by a meeting of the German states' science ministers next month.

Operating the academy will require modest government funding. It will need enough money to establish a robust technical staff, to help compile reports and organize public outreach. The manner in which it is funded will need to be designed to ensure that the academy retains political independence. One route would be for the academy to draw its money from the budget of the (politically neutral) federal president's office. The architects of the plan have yet to iron out all of these details.

Ultimately, a successful academy will have to earn not just the backing of scientists, but the trust of large segments of the public. It will be essential for the new body to proactively seek the engagement of the public from the outset. By giving due consideration to contentious issues, the academy should benefit German society by encouraging a healthy level of scientific discourse and improved public understanding of science.

\section{Reforms on drug safety}

\section{Critics of the US Food and Drug Administration have a valid point.}

T he US drug safety system is outdated, weak, disorganized and seriously underfunded, according to no less an authority than the Institute of Medicine (IOM). The Food and Drug Administration (FDA) has neither the money nor the muscle to police the safety of drugs already on the market, says a report released by the institute last week.

The FDA itself asked the IOM, which represents the most eminent figures in US medical research, to look into its drug-regulation process in 2004 after the withdrawal of the painkiller Vioxx, which was found to increase the risk of heart attacks and strokes (see Nature 432, 537; 2004). Vioxx provided an example of what can happen when drugs originally tested in limited numbers of people in clinical trials are put to work in the real world.

Subsequent examination has confirmed that the FDA's post-market safety efforts are paltry, particularly compared with its exhaustive pre-approval drug-evaluation process. That impression is confirmed by the IOM report, which makes more than two dozen recommendations for strengthening the US drug safety system.

The IOM committee, chaired by Sheila Burke, chief operating officer at the Smithsonian Institution, notes that the current balance of priorities at the FDA reflects an earlier era, when prescription medicines were usually taken one at a time, for short periods. It is less appropriate for today's chronically medicated, rapidly ageing, multiple-pill-popping population.

Many of the IOM's recommendations focus on strengthening the FDA's approach to ensuring the safety of drugs already on the market. The committee wants Congress to give the FDA the authority to fine companies that fail to run promised studies of their drugs once they are for sale. Companies commit to carrying out such studies when a drug is approved, but all too often these promises go unfulfilled.

The IOM also asks Congress to grant the FDA power to compel companies to change drug labels when new safety concerns arise. Under current law, the FDA can request but not demand these changes, often leading to protracted negotiations with drug firms. In the case of Vioxx, it spent 14 months getting a reference to heartattack risks added to the label, years before the drug was pulled.

The report says that newly approved drugs should carry a warning label - perhaps a black triangle - for their first two years or so on the market, to warn consumers about the limited state of knowledge on the drug. Direct advertising to consumers should also be restricted in this early period, it argues.

The IOM also proposes that a fixed, six-year term should be established for the post of FDA commissioner, in an attempt to detach it from the vicissitudes of the four-year presidential election cycle, and hence from party politics.
"Public concerns about drug safety need to be addressed, and senior figures in both parties have the issue in their sights."
Then there is the matter of money. The IOM wants Congress to give the FDA far more resources to monitor the safety of existing drugs. Rather than this being financed by the drug industry through user fees, it is emphatic that the money should come from the public purse, to make sure that the regulator is seen to be independent of excessive industry influence.

The radical changes that the IOM is recommending may face an uphill struggle in Congress. But public concerns about drug safety need to be addressed, and senior figures in both parties, from Senator Chuck Grassley (Republican, Iowa) to Senator Edward Kennedy (Democrat, Massachusetts), have the issue firmly in their sights. Congress should take some of the bold steps that the IOM report is suggesting, in order to restore the FDA's reputation for firm but fair drug regulation. 